\title{
Self-monitoring of blood glucose in type 2 \\ diabetes: Cross-sectional analyses in 1993, 1999 and 2009
}

\author{
JMM Evans ${ }^{1}$, Senior Lecturer in Public Health \\ D Mackison ${ }^{1}$, Research Fellow \\ A Emslie-Smith ${ }^{2}$, Principal in General Practice \\ Lawton J, Senior Research Fellow \\ School of Nursing, Midwifery and Health ${ }^{1}$, \\ University of Stirling \\ The Mill Practice, Dundee ${ }^{2}$ \\ Research Unit in Health, Behaviour and Change ${ }^{3}$, \\ University of Edinburgh
}

Correspondence to:

Dr Josie MM Evans PhD

School of Nursing, Midwifery and Health

University of Stirling

Stirling

FK9 4LA

Tel: 01786-466352

Fax: 01786-466333

Email: josie.evans@stir.ac.uk

Word Count (excluding Abstract, References and Tables): 1,622

Running title: Self-monitoring in type 2 diabetes 


\begin{abstract}
Aim: To characterise the numbers of reagent strips dispensed for self monitoring of blood glucose (SMBG) to patients with type 2 diabetes in Tayside, Scotland, in 1993, 1999 and 2009. Methods: A diabetes clinical information system in Tayside recordlinked to electronic dispensed prescribing records, was used to collate all dispensed prescribing records for three cross-sectional samples of patients with type 2 diabetes in $1993(n=5,728), 1999(n=8,109)$, and January $1^{\text {st }} 2009(n=16,450)$. The numbers of reagent strips dispensed during the relevant calendar year were calculated, and patients stratified by treatment. We also explored whether age, sex or material and social deprivation were associated with whether a patient received strips. Results: Proportions of people who received SMBG reagent strips increased from $15.5 \%$ in 1993, to $24.2 \%$ in 1999 to $29.8 \%$ in 2009 , as did numbers of strips dispensed. While the proportion of diet-treated patients who received reagent strips was still very low in $2009(5.6 \%)$, the proportion among those treated with oral agents tripled from $9.4 \%$ to $27.4 \%$ between 1993-2009. Over $90 \%$ of patients treated with insulin received reagent strips, and among non-insulin-treated patients this was commoner among women, younger people and less deprived groups. Conclusions: The numbers of reagent strips dispensed for SMBG has increased, and almost all insulin-treated patients receive strips. While few diet-treated patients receive strips, they are more extensively dispensed to those treated with oral agents. Given that SMBG is no longer routinely recommended in non-insulin treated patients, strategies to reduce unnecessary dispensing of reagent strips are needed.
\end{abstract}




\section{Introduction}

Self-monitoring of blood glucose (SMBG) is considered an integral part of treatment for people with type 1 diabetes, and those with type 2 diabetes who use insulin ${ }^{1,2}$. These patients can use SMBG readings to adjust insulin doses themselves, if appropriate, thereby assisting optimal glycaemic control. However, the benefits of SMBG among people with type 2 diabetes who do not use insulin are much less certain. Recent trials, reviews and meta-analyses have shown either no or very small effects of SMBG on glycaemic control ${ }^{3,4,5}$. Given that there is also concern over the high costs associated with $\mathrm{SMBG}^{6}$ and possible adverse psychological consequences $^{7,8}$, national guidelines state that routine monitoring is no longer recommended for patients who do not use insulin ${ }^{9,10}$, although it may benefit certain groups ( $e g$ users of sulponlyureas to reduce risk of hypoglycaemia) ${ }^{1}$.

While the benefits of SMBG amongst non-insulin treated patients have been questioned, some (albeit limited) research suggests there has been a large increase in the numbers of patients who undertake SMBG. A UK survey in primary care found that over $80 \%$ of patients, including those treated with oral agents, did some monitoring, albeit this research involved a small self-selected patient group ${ }^{11}$. Electronic prescribing records may provide a more objective picture of monitoring patterns, and a study using the General Practice Research Database (GPRD), indicated that prescriptions written for monitoring reagent strips among patients newly treated with oral agents increased from 19\% to $32 \%$ between 1993 and $1998^{12}$. The most recent analysis used IMS-Mediplus data for 40,094 patients with type 2 diabetes from 670 GP practices in the UK, and concluded that, in 2007, the proportion of patients treated with oral agents who self-monitored ranged from $36 \%$ to $58 \%$, depending on the particular (combinations of) oral agents ${ }^{13}$. However, perhaps more surprisingly, the same proportion for patients treated by diet/exercise only was found to be as high as $26 \%$.

Given the recently published guidance that patients who do not use insulin should not routinely self-monitor ${ }^{1}$, alongside the limited and sometimes contradictory evidence currently available regarding monitoring patterns and frequency, we have carried out a study of the numbers and patterns of reagent strips for SMBG dispensed to patients 
with type 2 diabetes in Tayside, Scotland, and compared results with those in 1993 and 1999 to observe changes over time. 


\section{Patients and Methods}

The Health Informatics Centre, University of Dundee ${ }^{14,15}$ works on the record-linkage of health care data to facilitate epidemiological and health services research in the population of Tayside, Scotland (estimated population of 396,960 in 2008). Recordlinkage is enabled by the widespread use of a unique health care identifier (CHI number) that is allocated to people when they register with a General Practitioner (GP) in Scotland. SCI-DC (Scottish Care Information - Diabetes Collaboration) is a validated population-based diabetes information system in Tayside, compiled by record-linking several independent data sources (formerly known as DARTS: Diabetes Audit and Research in Tayside, Scotland) ${ }^{14}$. Detailed clinical information is available via SCI-DC for all patients with diabetes. The Medicines Monitoring Unit (MEMO) database ${ }^{15}$, developed for pharmacoepidemiological research, keeps computerised records of every prescription dispensed to Tayside residents, including those for self-monitoring equipment.

From SCI-DC, we obtained prevalence estimates in Tayside for people who had been diagnosed with type 2 diabetes: at any time in 1993 and 1999, and prior to January $1^{\text {st }}$ 2009. For every patient, we collated all prescriptions dispensed for blood reagent strips during the relevant calendar year. We were able to calculate the exact numbers of reagent strips dispensed for SMBG from details on the prescription. We recordlinked these data to clinical and demographic information. We then categorised patients into those who had also received any prescription for insulin during the year as insulin-treated, those who received prescriptions for oral agents only as oraltreated, and the remaining patients as diet-treated. For the 2009 sample, we were also able to identify patients in the oral-treated group who had received any prescription for sulphonylureas. We investigated whether monitoring patterns were associated with age, sex and a postcode measure of social and material deprivation (SIMD) that classified people into quintiles of deprivation. This incorporates information on income, employment, health and disability, education, skills and training, and access to services, for small geographical areas ${ }^{16}$. To explore factors associated with whether or not a patient was dispensed reagent strips for any SMBG, we used logistic regression analysis to obtain adjusted odds ratios (with $95 \%$ confidence intervals) for 
these explanatory variables independently. Given there were only three variables, we entered all three into the model simultaneously. 


\section{Results}

In 1993, 219,376 reagent strips for blood glucose monitoring were dispensed to patients with type 2 diabetes in Tayside, compared with 1,058,384 in 1999 and 1,777,664 in 2009. These were dispensed to 5,728 and 8,109 patients in 1993 and 1999 respectively, and 16,450 patients who had type 2 diabetes on $1^{\text {st }}$ January 2009. Overall, the proportions of people who were dispensed any reagent strips for SMBG increased from $15.5 \%$ in 1993 , to $24.2 \%$ in 1999 to $29.8 \%$ in 2009.

Table 1 shows that the largest increase in reagent strips dispensed for SMBG occurred among people treated with oral agents. While the proportion of diet-treated patients who were dispensed reagent strips was still very low in 2009 (5.6\%), the proportion for those treated with oral agents tripled from $9.4 \%$ to $27.4 \%$ during this time. The majority of patients treated with insulin received reagent strips for SMBG; this proportion is now over $90 \%$. Among patients who received any reagent strips, the total numbers of strips dispensed also increased among patients treated with oral agents and insulin over the study period. The mean number of strips dispensed among insulin-treated patients is sufficient for daily monitoring. For those treated with oral agents, sufficient strips are dispensed for monitoring 3-4 times weekly. The proportion monitoring and the mean number of strips dispensed were higher among patients who were treated with sulphonylureas. However, there was still one fifth of patients treated with metformin and other oral agents who were receiving reagent strips for $\mathrm{SMBG}$.

Table 2 shows that receiving reagent strips for SMBG among patients not treated with insulin is more common among women and less deprived groups, but decreases with increasing age, with the odds ratios indicating independent effects of each of these factors. The associations are particularly evident for patients treated with oral agents. 


\section{Discussion}

This study has confirmed a general increase in reagent strips dispensed for SMBG among all patients with type 2 diabetes over the past 15 years. While it is encouraging that over $90 \%$ of insulin-treated patients receive reagent strips, and obtain sufficient numbers to monitor daily, the increase in non insulin treated patients receiving reagent strips may be cause for concern, particularly among patients treated with oral agents.

This study measured the number of reagent strips that were dispensed to patients in community pharmacies. Although we cannot be sure whether patients actually used all the strips that were dispensed to them, and they may also have received strips from other sources, the study has identified clear trends over time. We also consider that dispensed prescribing records for an entire diabetic population may provide a more objective measure of actual monitoring behaviour than self-report from selected samples of patients. Nevertheless the finding that only $5.6 \%$ of diet-treated patients received reagent strips for SMBG stands in stark contrast to the $26 \%$ reported using electronic IMS-Mediplus data from 670 GP practices $^{13}$. That study used QoF data (Quality and Outcomes Framework) to locate patients with diabetes, hence it was able to identify only those who were receiving active treatment and monitoring. In contrast, the SCI-DC diabetes register in Tayside record-links information from several independent data sources and has high sensitivity and specificity for identifying all patients with diabetes ${ }^{14}$. Not only is the IMS-Mediplus study likely to have under-ascertained diet treated patients, patients who monitored were, by definition, more likely to have been identified. We therefore consider that our figure of $5.6 \%$ is a more realistic estimate of the prevalence of patients with type 2 diabetes who receive reagent strips for SMBG but who are not treated with oral agents or insulin.

The greatest increase in reagent strips dispensed for SMBG was observed in patients treated with oral agents, with $27.4 \%$ receiving strips in 2009 . The mean number of strips per patient would enable monitoring 3-4 times per week. In some practices in Scotland, GPs are no longer writing prescriptions for reagent strips for such patients, and it may be that this figure has decreased slightly since 2009. However, although this figure is also lower than in the IMS-Mediplus study, probably for the reasons 
already discussed, it is still substantial, given that routine monitoring is not recommended ${ }^{1}$. While the SIGN guidelines specify certain groups who may benefit from monitoring ${ }^{1}$, for example patients using sulphonylureas who are at high risk of hypoglycaemia, this is unlikely to apply to over one third of these patients.

In summary, given the recent introduction of guidelines recommending that people who are not treated with insulin do not routinely undertake SMBG, alongside increased rationing of monitoring strips, the challenge is to identify patients for whom carrying out monitoring is unlikely to be beneficial and to dissuade them from doing so. Although we have identified several factors associated with receiving increased numbers of reagent strips for SMBG; specifically, being younger, female and from a less deprived area, it is not clear whether this arises from patient and/or prescriber expectations or behaviours. The increasing variety, availability and ease of use of selfmonitoring testing kits, alongside marketing by their manufacturers, may be fuelling patient demand. To reduce unnecessary levels of monitoring, further research is therefore needed drawing upon patients' and health professionals' understandings, motivation and experience of monitoring, particularly among those patients who monitor most frequently. 


\section{Acknowledgements}

Acknowledgements to the Health Informatics Centre, University of Dundee for provision of data.

\section{Funding}

This study was part-funded by Diabetes UK (ref RD03/0002637). The researchers were independent from the funding body.

\section{Conflict of Interest}

No Conflicts of Interest have been declared by the authors. 


\section{References}

1. Scottish Intercollegiate Guidelines Network (SIGN) (2010). Management of diabetes. A national clinical guideline. 116.

2. Reynolds RM, Webb DJ. Recommendations and conclusions from a minisymposium on self-blood glucose monitoring. $J R$ Coll Physicians Edinb 2006;36:155-8.

3. Farmer AJ, Wade AN, French DP, Simon J, Yudkin P, Gray A, Craven A, Goyder L, Holman RR, Mant D, Kinmonth A-L, Neil HAW on behalf of the DiGEM Trial Group. Blood glucose self-monitoring in type 2 diabetes: a randomised controlled trial. Health Technol Assess 2009; 13:15.

4. Welschen LM, Bloemendal E, Nijpels G, Dekker JM, Heine RJ. Selfmonitoring of blood glucose in patients with type 2 diabetes who are not using insulin: a systematic review. Diabetes Care 2005; 28.

5. Towfigh A, Romanova M, Weinreb JE, Munjas B, Suttorp MJ, Zhou A, Shekelle PG. Self-monitoring of blood glucose levels in patients with type 2 diabetes mellitus not taking insulin.: A meta-analysis. Am J Managed Care 2008; 14:

6. Davidson MB. Counterpoint: self-monitoring of blood glucose in type 2 diabetic patients not receiving insulin: a waste of money. Diabetes Care $2005 ; 28: 1531-3$.

7. Franciosi M, Pellegrini F, De Berardis G, Belfiglio M, Cavaliere D, et al. The impact of blood glucose self-monitoring on metabolic control and quality of life in type 2 diabetic patients. Diabetes Care 2001;24:1870-7.

8. Peel E, Parry O, Douglas M, Lawton J. Blood glucose self-monitoring in noninsulin treated type 2 diabetes: a qualitative study of patients' perspectives.

Brit J General Prac 2004;54:183-8.

9. Heller et al. NHS Diabetes report: Self monitoring of blood glucose in noninsulin-treated type 2 diabetes, NHS Diabetes, 2010.

10. Clar C, Barnard K, Cummins E, Royle P, Waugh N. Self-monitoring of blood glucose in type 2 diabetes: systematic review. Health Technol Assess 2010; 14. 
11. Stewart D, McCaig D, Davie A, Juroszek L, Blackwood L, Findlay N, McCarthy S. Glucose self-monitoring in primary care: a survey of current practice. J Clin Pharm Ther 2004; 29:273-277.

12. Gulliford M, Latinovic R. Variations in glucose self-monitoring during oral hypoglycaemic therapy in primary care. Diabetic Medicine 2004; 21:685-690.

13. Belsey JD, Pittard JB, Rao S, Urdahl H, Jameson K, Dixon T. Self blood glucose monitoring in type 2 diabetes. A financial impact analysis based on UK primary care. Int J Clin Pract 2009; 63:439-448.

14. Morris AD, Boyle DIR, MacAlpine $\mathrm{R}$ et al. The diabetes audit and research in Tayside, Scotland (DARTS) study: electronic record-linkage to create a diabetes register. $\mathrm{Br}$ Med J 1997; 315:5245-28.

15. Evans JMM, McDevitt DG, MacDonald TM. The Tayside Medicines Monitoring Unit (MEMO): A record-linkage system for pharmacovigilance. Pharmaceut Med 1995; 9:177-184.

16. Using the Scottish Index of Multiple Deprivation 2006: Guidance leaflet. http://www.scotland.gov.uk/Publications/2006/10/13142841/1. 


\section{Tables}

\begin{tabular}{|c|c|c|c|}
\hline & $\begin{array}{c}\text { No. of } \\
\text { patients }\end{array}$ & $\begin{array}{l}\text { Nos. of patients who } \\
\text { received reagent strips } \\
\text { for SMBG }\end{array}$ & $\begin{array}{c}\text { Mean no. of strips } \\
\text { dispensed per } \\
\text { patient over } 12 \\
\text { month period } \\
\text { (mean in patients } \\
\text { who received any } \\
\text { strips) }\end{array}$ \\
\hline \multicolumn{4}{|l|}{1993} \\
\hline Diet & 2,240 & $57(2.5 \%)$ & $4.1(160.2)$ \\
\hline Oral & 2,652 & $250(9.4 \%)$ & $13.3(140.7)$ \\
\hline Insulin & 836 & $557(66.6 \%)$ & $195.5(293.5)$ \\
\hline All & 5,728 & $864(15.5 \%)$ & $36.3(240.5)$ \\
\hline \multicolumn{4}{|l|}{1999} \\
\hline Diet & 2,598 & $88(3.4 \%)$ & $5.0(148.3)$ \\
\hline Oral & 4,203 & $716(17.0 \%)$ & $29.0(170.3)$ \\
\hline Insulin & 1,308 & $1,099(84.0 \%)$ & $349.1(415.5)$ \\
\hline All & 8,109 & $1,903(23.5 \%)$ & $73.0(310.9)$ \\
\hline \multicolumn{4}{|l|}{2009} \\
\hline Diet & 5,167 & $289(5.6 \%)$ & $8.4(150.6)$ \\
\hline $\begin{aligned} \text { Oral } & \\
\text { - } & \text { Any sulph } \\
\text { - } & \text { No sulph }\end{aligned}$ & $\begin{array}{l}8,856 \\
\text { - } \quad 4,518 \\
\text { - } 4,338\end{array}$ & $\begin{array}{l}2,427(27.4 \%) \\
\text { - } \quad 1,513(33.5 \%) \\
\text { - } \quad 914(21.2 \%)\end{array}$ & $\begin{array}{l}54.4(198.3) \\
\text { - } \quad 70.6(210.8) \\
\text { - } \quad 37.4(177.8)\end{array}$ \\
\hline Insulin & 2,427 & $2,186(90.1 \%)$ & $516.2(573.1)$ \\
\hline All & 16,450 & $4,902(29.8 \%)$ & $362.6(362.3)$ \\
\hline
\end{tabular}

Table 1: Numbers of patients receiving reagent strips for SMBG, and mean numbers of reagent strips dispensed in 1993, 1999 and 2009. 


\begin{tabular}{|c|c|c|c|c|c|c|}
\hline & \multicolumn{3}{|c|}{ Diet-treated } & \multicolumn{3}{|c|}{ Treated with oral agents } \\
\hline & Total & $\begin{array}{c}\text { Total } \\
\text { monitoring } \\
(\%)\end{array}$ & $\begin{array}{l}\text { Adj. OR } \\
(95 \% \mathrm{CI})\end{array}$ & Total & $\begin{array}{c}\text { Total } \\
\text { monitoring } \\
(\%)\end{array}$ & $\begin{array}{l}\text { Adj. OR } \\
(95 \% \text { CI })\end{array}$ \\
\hline \multicolumn{7}{|l|}{ Sex } \\
\hline Male & 2,582 & $148(5.7 \%)$ & 1.00 & 4,939 & $\begin{array}{c}1,330 \\
(26.9 \%)\end{array}$ & 1.00 \\
\hline Female & 2,296 & $141(6.1 \%)$ & $\begin{array}{c}1.13 \\
(0.89-1.44)\end{array}$ & 3,917 & $\begin{array}{c}1,097 \\
(28.0 \%)\end{array}$ & $\begin{array}{c}1.12 \\
(1.02-1.23)\end{array}$ \\
\hline \multicolumn{7}{|l|}{ Age } \\
\hline$<45 \mathrm{yrs}$ & 299 & $17(5.7 \%)$ & 1.00 & 525 & $\begin{array}{c}180 \\
(34.3 \%)\end{array}$ & 1.00 \\
\hline $45-54 \mathrm{yrs}$ & 590 & $30(5.1 \%)$ & $\begin{array}{c}0.89 \\
(0.48-1.63)\end{array}$ & 1,283 & $\begin{array}{c}393 \\
(30.6 \%)\end{array}$ & $\begin{array}{c}0.82 \\
(0.66-1.02)\end{array}$ \\
\hline $55-64$ yrs & 1,131 & $84(7.4 \%)$ & $\begin{array}{c}1.23 \\
(0.72-2.12)\end{array}$ & 2,287 & $\begin{array}{c}654 \\
(28.6 \%)\end{array}$ & $\begin{array}{c}0.73 \\
(0.59-0.89)\end{array}$ \\
\hline $65-74$ yrs & 1,388 & $87(6.3 \%)$ & $\begin{array}{c}1.04 \\
(0.61-1.78)\end{array}$ & 2,691 & $\begin{array}{c}763 \\
(28.4 \%)\end{array}$ & $\begin{array}{c}0.71 \\
(0.58-0.87)\end{array}$ \\
\hline $75+y r s$ & 1,470 & $71(4.8 \%)$ & $\begin{array}{c}0.78 \\
(0.48-1.35)\end{array}$ & 2,070 & $\begin{array}{c}437 \\
(21.1 \%)\end{array}$ & $\begin{array}{c}0.47 \\
(0.38-0.58)\end{array}$ \\
\hline \multicolumn{7}{|c|}{ Deprivation (quintiles) } \\
\hline $\begin{array}{l}1 \text { (most } \\
\text { deprived) }\end{array}$ & 792 & $29(3.7 \%)$ & 1.00 & 1,527 & $\begin{array}{c}348 \\
(22.8 \%)\end{array}$ & 1.00 \\
\hline 2 & 862 & $38(4.4 \%)$ & $\begin{array}{c}1.22 \\
(0.74-1.99)\end{array}$ & 1,585 & $\begin{array}{c}388 \\
(24.5 \%)\end{array}$ & $\begin{array}{c}1.12 \\
(0.95-1.33)\end{array}$ \\
\hline 3 & 856 & $58(6.8 \%)$ & $\begin{array}{c}1.87 \\
(1.18-2.95)\end{array}$ & 1,670 & $\begin{array}{c}496 \\
(29.7 \%)\end{array}$ & $\begin{array}{c}1.50 \\
(1.28-1.77)\end{array}$ \\
\hline 4 & 1,515 & $103(6.8 \%)$ & $\begin{array}{c}1.88 \\
(1.23-2.86)\end{array}$ & 2,605 & $\begin{array}{c}772 \\
(29.6 \%)\end{array}$ & $\begin{array}{c}1.53 \\
(1.32-1.77)\end{array}$ \\
\hline $\begin{array}{l}5 \text { (least } \\
\text { deprived) }\end{array}$ & 794 & $56(7.1 \%)$ & $\begin{array}{c}1.95 \\
(1.23-3.09)\end{array}$ & 1,358 & $\begin{array}{c}388 \\
(28.6 \%)\end{array}$ & $\begin{array}{c}1.47 \\
(1.24-1.74)\end{array}$ \\
\hline Not known & 59 & $5(8.5 \%)$ & $\begin{array}{c}2.32 \\
(0.86-6.22)\end{array}$ & 111 & $\begin{array}{c}35 \\
(31.5 \%)\end{array}$ & $\begin{array}{c}1.55 \\
(1.02-2.35)\end{array}$ \\
\hline
\end{tabular}


Table 2: Results of logistic regression to evaluate effects of age, sex and deprivation on whether patients received any SMBG reagent strips in 1999, stratified by treatment type 